\title{
Review of extended-release niacin/laropiprant fixed combination in the treatment of mixed dyslipidemia and primary hypercholesterolemia
}

This article was published in the following Dove Press journal:

Vascular Health and Risk Management

30 October 2009

Number of times this article has been viewed

\author{
Klaus G Parhofer \\ Medical Department II Grosshadern, \\ University of Munich, Germany
}

\begin{abstract}
Although statins reduce cardiovascular morbidity and mortality further risk reduction is needed. In this respect low HDL-cholesterol concentrations and/or elevated triglyceride concentrations may be potential treatment targets. Niacin (nicotinic acid) is an effective drug which increases the plasma concentration of high-density lipoprotein (HDL)-cholesterol and decreases the concentration of low-density lipoprotein (LDL)-cholesterol, triglycerides and lipoprotein(a). Clinical studies indicate that niacin can significantly reduce the risk for cardiovascular events. However, niacin is not very commonly used because of significant side effects (especially flushing). Laropiprant is a potent selective antagonist of PGD2-receptor subtype-1 and can thus reduce niacin-induced flushing. Although the addition of laropiprant will reduce the frequency of flushing, it will not completely eliminate this side effect. Laropiprant does not change the effect of niacin on lipids or other side effects of niacin (ie, gastro-intestinal problems, glucose elevation). The combination of niacin with laropiprant may therefore enable use of niacin at higher doses and therefore exploit the full potential of the drug. Endpoint studies that will be published over the next few years will show whether this treatment modality also translates into clinical effect in patients treated with statins. Until publication of these studies niacin/laropiprant should be used only in high-risk patients not achieving lipid goals on statins.
\end{abstract}

Keywords: nicotinic acid, flushing, hyperlipidemia, dyslipoproteinemia

\section{Introduction}

Atherosclerosis and its complications such as myocardial infarction, stroke and peripheral vascular disease remain important reasons of mortality and morbidity in industrialized and developing countries. ${ }^{1}$ Therefore, it is of utmost importance to develop strategies for treating and preventing atherosclerosis. Atherosclerosis is seen as a dynamic process which is initiated and maintained by the interaction of risk factors and immunologic processes. ${ }^{2}$ While many risk factors such as dyslipidemia, diabetes, smoking and hypertension are well established the mechanisms linking these risk factors with atherosclerosis are less well known.

Therefore, strategies to reduce risk factors are still our most powerful tools to prevent and treat atherosclerosis. Although many approaches have been proven successful, the treatment of dyslipidemia is probably the one which mediates the biggest benefit. Most of our current strategies with respect to lipids focus on low-density lipoprotein (LDL)-cholesterol reduction. This relates to several aspects. First, the mechanism by which elevated concentrations of LDL-particles result in atherosclerosis is relatively well understood. Especially after oxidation and/or modification LDL particles are central for inducing the immunologic processes underlying atherosclerosis. Second, the
Correspondence: Klaus G Parhofer Medical Department II__Grosshadern, University Munich, Marchioninistr. 15, 81377 Munich, Germany $\mathrm{Tel}+49$ 89-7095-3010

Fax +49-89-7095-8879 Email klaus.parhofer@med. uni-muenchen.de 
epidemiological relationship between elevated total cholesterol and atherosclerosis can be attributed to a large extent to elevated LDL-cholesterol. Finally, many studies have shown that lowering LDL-cholesterol by statins or other forms of therapy can reduce morbidity and mortality from atherosclerosis. ${ }^{3,4}$

The importance of treating abnormal lipid concentrations to prevent atherosclerotic events is also reflected in the guidelines of professional associations such as the American Heart Assocation, European Society of Cardiology and others. ${ }^{5,6}$ These guidelines have focused on LDL-cholesterol reduction although over the last decade it has been recognized that triglycerides, high-density lipoprotein (HDL)-cholesterol, and lipoprotein(a) are not only important as predictors of atherosclerotic events but are potential therapeutic targets. ${ }^{7}$ This is very important since LDL-lowering strategies can obviously not prevent all atherosclerotic events. In fact, most studies report a relative risk reduction of $25 \%$ to $35 \%$, which means that on average the majority of events cannot be prevented. ${ }^{3,4}$ Several strategies can be developed to improve this result. It is conceivable that more aggressive LDL-cholesterol reduction might further prevent atherosclerotic events. Another approach would be to address other lipidologic risk factors, such as triglycerides, HDL-cholesterol, lipoprotein(a), and probably also postprandial lipoproteins and specific subfractions of LDL and/or HDL.

\section{Current treatment strategies and its limitations}

The current treatment strategy strongly focuses on LDLcholesterol reduction (Table 1). Depending on the absolute risk, an LDL-cholesterol of $<100 \mathrm{mg} / \mathrm{dL}$ (optional $<70 \mathrm{mg} / \mathrm{dL}$ ) in patients with high risk (ie, $>20 \%$ event rate/10 years) or an LDL-cholesterol $<130 \mathrm{mg} / \mathrm{dL}$ (intermediate risk) or an LDL-cholesterol $<160 \mathrm{mg} / \mathrm{dL}$ (low risk) is set as a treatment goal..$^{5}$ The primary drug treatment used to achieve these goals is usually a statin. However, several other drugs are available to modify lipid levels. These drugs differ in mode of action, effect on lipids and degree of evidence with respect to reducing cardiovascular morbidity and mortality. Table 2 summarizes the various lipid-modifying drugs.

In patients with normal triglyceride and HDL-cholesterol levels but elevated LDL-cholesterol levels despite statin therapy several approaches are possible. These include increasing the dose of the statin, switching to a more potent statin, combining the statin with a cholesterol absorption inhibitor (ezetimibe) or combining a statin with a bile acid binding compound (for example colesevelam). For patients on a statin with abnormal triglyceride and/or HDL-cholesterol concentrations combination therapy of a statin with niacin may be a treatment option. The combination of statins with either a fibrate or omega-3 fatty acids may be alternatives. In patients with isolated hypertriglyceridemia primary fibrate or niacin therapy or treatment with omega-3 fatty acids may be considered.

However, it must be acknowledged that not all treatment strategies are covered by convincing end point data and some of the suggested combination therapies are associated with considerable side effects. This is particularly true for the combination of a statin with niacin or with a fibrate.

\section{Niacin (nicotinic acid)}

Niacin was the first lipid-lowering drug developed. ${ }^{8}$ Despite clear lipid-lowering effects and the proof of clinical benefit in early prevention studies, niacin is not used very often in clinical practice. There are multiple reasons, the most important being the high rate of side effects and the stronger LDLcholesterol reduction and the better documented effects of statins. ${ }^{4,9}$ Although extended-release forms of niacin (ERN) have somewhat less side effects in clinical practice, niacin is rarely used.

Table I Low-density lipoprotein (LDL) goals in different patient groups ${ }^{5}$

\begin{tabular}{llc}
\hline Risk group & LDL cholesterol goal & Threshold for drug therapy \\
\hline $\begin{array}{l}\text { High risk (CAD or CAD equivalent: peripheral } \\
\text { vascular disease, abdominal aortic aneurysm, }\end{array}$ & $<100 \mathrm{mg} / \mathrm{dL}(2.6 \mathrm{mmol} / \mathrm{L})$ optional: & $\geq 100 \mathrm{mg} / \mathrm{dL}(2.6 \mathrm{mmol} / \mathrm{L})$ \\
$\begin{array}{l}\text { cerebrovascular disease, diabetes) } 10 \text {-year } \\
\text { risk }>20 \%\end{array}$ & $<70 \mathrm{mg} / \mathrm{dL}(1.8 \mathrm{mmol} / \mathrm{L})$ & \\
$\begin{array}{l}\text { Moderately high risk: } \geq 2 \text { risk factors } 10 \text {-year } \\
\text { risk } 10 \%-20 \%\end{array}$ & $<130 \mathrm{mg} / \mathrm{dL}(3.4 \mathrm{mmol} / \mathrm{L})$ & $\geq 130 \mathrm{mg} / \mathrm{dL}(3.4 \mathrm{mmol} / \mathrm{L})$ \\
$\begin{array}{l}\text { Moderate risk } \geq 2 \text { risk factors } \\
\text { I0 year risk }<10 \%\end{array}$ & $<130 \mathrm{mg} / \mathrm{dL}(3.4 \mathrm{mmol} / \mathrm{L})$ & $\geq 160 \mathrm{mg} / \mathrm{dL}(4.1 \mathrm{mmol} / \mathrm{L})$ \\
Lower risk $\leq 1$ risk factor & $<160 \mathrm{mg} / \mathrm{dL}(4.1 \mathrm{mmol} / \mathrm{L})$ & $\geq 190 \mathrm{mg} / \mathrm{dL}(4.9 \mathrm{mmol} / \mathrm{L})$ \\
\hline
\end{tabular}

Notes: Risk factors: smoking, hypertension, low HDL-cholesterol ( $<40 \mathrm{mg} / \mathrm{dL}$ ), positive family history for premature CAD (men $<55$ years, women $<65$ years), age (men $\geq 45$ years, women $\geq 55$ years).

Abbreviations: CAD, coronary artery disease; HDL, high-density lipoprotein; LDL, low-density lipoprotein. 
Table 2 Effect of lipid-modifying drugs

\begin{tabular}{|c|c|c|}
\hline & Lipid effect & $\begin{array}{l}\text { Effect on } \\
\text { morbidityl } \\
\text { mortality }\end{array}$ \\
\hline Statins & LDL $\downarrow \downarrow \downarrow$, TG $\downarrow$ & $++++/-$ \\
\hline Fibrates & TG $\downarrow \downarrow \downarrow, \mathrm{HDL} \uparrow, \mathrm{LDL} \downarrow$ & $+1-$ \\
\hline $\begin{array}{l}\text { Nicotinic } \\
\text { acid/niacin }\end{array}$ & LDL $\downarrow \downarrow$, TG $\downarrow \downarrow, \mathrm{HDL} \uparrow \uparrow$ & + \\
\hline $\begin{array}{l}\text { Cholesterol } \\
\text { adsorption inhibitors }\end{array}$ & LDL $\downarrow \downarrow$ & 0 \\
\hline Bile acid binding resins & LDL $\downarrow \downarrow$, TG $\uparrow$ & + \\
\hline Omega-3-fatty acids & TG $\downarrow \downarrow, H D L \uparrow$ & $0 /(+)$ \\
\hline
\end{tabular}

Abbreviations: HDL, high-density lipoprotein; LDL, low-density lipoprotein; TG, total triglycerides.

\section{Effect of niacin on lipids}

The effects of niacin on plasma lipids depend on the dose and the underlying dyslipoproteinemia. Clinically significant changes of lipid levels are usually seen at doses of $1 \mathrm{~g} /$ day or higher, but doses of $1.5 \mathrm{~g} /$ day or $2 \mathrm{~g} /$ day are necessary to achieve the full effect on lipids. Generally, niacin decreases total cholesterol, triglycerides, LDL-cholesterol and lipoprotein(a), while it increases HDL-cholesterol. ${ }^{10,11}$ The effects of niacin are summarized in Table 3.

Although niacin was initially used as monotherapy or in combination with fibrates or bile acid binding compounds, nowadays it is primarily indicated in combination with statins. ${ }^{12,13}$ It is therefore important to evaluate whether the changes described above also hold true in patients on statin therapy. In a recent study comparing 4 treatment arms in 293 patients with dyslipidemia it was shown that rosuvastatin (40 mg/day), simvastatin with ezetimibe (40 mg/10 mg per day), rosuvastatin with niacin $(20 \mathrm{mg} / 2000 \mathrm{mg}$ per day), and atorvastatin with niacin $(40 \mathrm{mg} / 2000 \mathrm{mg}$ per day) resulted in an identical reduction of LDL-cholesterol (-50\% to $-55 \%)$. Therapies without niacin resulted in an increase of HDLcholesterol of approximately $5 \%$ to $10 \%$, while the increase in combination therapy using niacin was $22 \%$ to $25 \%$. In addition, combinations using niacin decreased triglycerides by $40 \%$ to $50 \% .{ }^{14}$ This indicates that the effect of niacin on plasma lipids is independent of the underlying baseline medication.

Generally it can be assumed that niacin at a dose of more than $1.5 \mathrm{~g} /$ day will decrease LDL-cholesterol, triglycerides and lipoprotein(a) by approximately $20 \%$, while it will increase HDL-cholesterol also by approximately $20 \%$ ("rule of $20 \% ") .9,15$

\section{Mechanism of action of niacin}

The mechanism by which niacin affects plasma lipids is not completely understood. ${ }^{16}$ Niacin binds to a specific G-protein
Table 3 Effect of nicotinic acid on lipids, lipoprotein and apoproteins

\begin{tabular}{ll}
\hline Lipoprotein class & Effects \\
\hline Apo B-containing lipoproteins & VLDL $\downarrow$ \\
& IDL $\downarrow$ \\
& LDL $\downarrow$ \\
& Apo B $\downarrow$ \\
& Small-dense LDL $\downarrow$ \\
& Lp(a) $\downarrow$ \\
Apo A-containing lipoproteins & HDL $\uparrow$ \\
& HDL $\uparrow$ \\
& HDL $\sim$ \\
Important ratios & Apo A-I $\uparrow$ \\
& Total cholesterol/ \\
& HDL cholesterol $\downarrow$ \\
& LDL-cholesterol/ \\
& HDL cholesterol $\downarrow$ \\
& Apo B/Apo A-I $\downarrow$ \\
& HDL $/ H D L_{3} \uparrow$ \\
& Lp A-I/Lp A-I + \\
& A-II $\uparrow$ \\
\hline
\end{tabular}

Abbreviations: Apo, apoprotein; HDL, high-density lipoprotein; LDL, low-density lipoprotein; Lp, lipoprotein; VLDL, very low-density lipoprotein.

receptor (GPR109A) which is expressed in adipose tissue and in epidermal cells. ${ }^{17}$ The binding of niacin to the receptor results in a decreased lipolysis and thus a dose-dependent decreased release of free fatty acids into plasma. This decrease is followed by a rebound. ${ }^{18}$ Despite this rebound the decreased flow of free fatty acids to the liver results in a decreased secretion of very low-density lipoprotein (VLDL) particles. ${ }^{19}$ Hepatic VLDL secretion is determined by a number of regulators, of which free fatty acid concentration is probably the most important. The changes in LDL concentration and thus LDL-cholesterol are probably secondary phenomena. Since LDL are to a large extent the metabolic product of VLDL delipidation, it is evident that a decreased VLDL secretion rate will also reduce concentration of LDL particles. Niacin also affects the LDL subtype distribution, resulting in a shift from small dense LDL particles to more buoyant lipoproteins. ${ }^{20}$ This results in less atherogenic LDL particles. For HDL-cholesterol, it is believed that the deceased concentration of VLDL particles will result in a decreased interaction with HDL particles leading to higher HDL-cholesterol concentrations. Whether and to what extent direct effects on HDL metabolism are important in inducing the raise in HDL-cholesterol is unknown. Furthermore, niacin also results in a shift within the HDL fraction; thus the HDL2: HDL3 ratio is increased. Again this is considered beneficial 
in relation to atherosclerosis. The mechanism underlying the reduction of lipoprotein(a) during therapy with niacin is unknown. However, it is an interesting observation that lipoprotein(a) concentrations can be decreased only by drugs that affect lipoprotein production, such as niacin or apo B antisense oligo-nucleotides such as mipomersen. ${ }^{21}$ Drugs that primarily affect the catabolism of lipoproteins, such as statins, ezetimibe, or bile acid-binding compounds, usually have no effect on lipoprotein(a) concentration. Whether and to what extent niacin affects postprandial lipoprotein metabolism is unknown. However, it can be assumed that niacin will not only improve fasting lipids but also postprandial lipoprotein metabolism.

\section{Clinical studies with niacin}

A number of studies have shown that niacin can decrease surrogate parameters of atherosclerosis and clinical events (Table 4). ${ }^{122-26}$ The HATS trial tested the hypothesis that lipid-modifying (simvastatin and niacin) and antioxidant therapy provide independent and additive benefits for patients with coronary heart disease and low HDL-cholesterol. ${ }^{22}$ The study compared placebo vs simvastatin/niacin vs antioxidants vs simvastatin/niacin with antioxidants. The study showed no effect of antioxidants but proved that patients receiving simvastatin in combination with niacin had a significant reduction in cardiovascular events $(60 \%$ relative risk reduction for simvastatin/niacin vs no simvastatin/niacin). However, as in previous studies it was not tested whether niacin provides an additional effect over statin monotherapy. The extent of risk reduction $(60 \%)$ indicates, however, that the effect is more prominent than could be expected by simvastatin alone.

The coronary drug project evaluated the effect of niacin as monotherapy in patients with established coronary heart disease. ${ }^{11}$ After 6 years of treatment the clinical event rate was decreased by $27 \%$ in the niacin group. Furthermore, a secondary analysis (after 15 years) showed a decrease in total mortality of $11 \%{ }^{23}$

\section{Side effects of niacin}

Despite these convincing data on lipids and clinical events, niacin is not very often used in clinical practice because of side effects. However, not all studies report high rates of discontinuation. ${ }^{27-29}$ Although the rate of flushing was decreased by using slow-release formulations it stills represents a hurdle for its clinical use. Furthermore, gastrointestinal symptoms such as diarrhea, nausea and reduced appetite as well as elevated glucose concentrations were reported.

In humans the flush following the oral intake of niacin is the result of a cutaneous vasodilatation which is mediated by prostaglandin D2 (PGD2). ${ }^{30}$ In the skin niacin binds to the same receptor that mediates the lipid-modulating effects. In Langerhans cells of the epidermis this binding induces the formation of PDG2 which then binds to a specific receptor (prostaglandin-D2-receptor-1). This receptor mediates vasodilation and thus flushing. ${ }^{31}$ In humans this receptor is present in the vessels of the skin, in the small intestine, in the brain and in the lung. ${ }^{31,32}$ Acetylsalicylic acid and other nonsteroidal anti-inflammatory drugs (NSAID)s have been found to have some efficacy suppressing niacin-induced

Table 4 Selected randomized controlled trials of nicotinic acid ${ }^{12,22-26}$

\begin{tabular}{|c|c|c|c|c|c|}
\hline Study & Intervention & $\begin{array}{l}\text { Patients receiving } \\
\text { treatment/total }\end{array}$ & Change in lipids \% & Duration years & Outcome \\
\hline CDP (1975) & Nicotinic acid & III9/834I & $\begin{array}{l}\text { Chol }-10 \\
\text { TG }-26 \\
\text { HDL NR } \\
\text { LDL NR }\end{array}$ & 6 & Decreased nonfatal MI \\
\hline CDP follow up (1986) & Nicotinic acid & III9/834I & See above & 15 & Decreased total mortality \\
\hline CLAS (1987) & $\begin{array}{l}\text { Nicotinic acid }+ \\
\text { colestipol }\end{array}$ & $80 / 162$ & $\begin{array}{l}\mathrm{HDL}+37 \\
\mathrm{LDL}-43 \\
\mathrm{TG}-22\end{array}$ & 2 & $\begin{array}{l}\text { Decreased coronary atherosclerosis } \\
\text { on angiography }(P=0.002)\end{array}$ \\
\hline HATS (200I) & $\begin{array}{l}\text { Nicotinic acid + } \\
\text { simvastatin }\end{array}$ & $38 / 160$ & $\begin{array}{l}\mathrm{HDL}+26 \\
\mathrm{LDL}-42 \\
\mathrm{TG}-36\end{array}$ & 3 & $\begin{array}{l}\text { Decreased MACE (first event: death, } \\
\text { MI, stroke, revascularization) }\end{array}$ \\
\hline ARBITER 2 (2004) & $\begin{array}{l}\text { Nicotinic acid + } \\
\text { statin }\end{array}$ & $87 / 167$ & $\begin{array}{l}\mathrm{HDL}+2 \mathrm{I} \\
\mathrm{LDL}-3 \\
\mathrm{TG}-13\end{array}$ & 1 & $\begin{array}{l}\text { Decreased progression of carotid IMT } \\
(P=0.08) \text {; significant in patients with } \\
\text { insulin resistance }\end{array}$ \\
\hline
\end{tabular}

Abbreviations: HDL, high-density lipoprotein; IMT, intima-media thickness; LDL, low-density lipoprotein; MACE, major adverse cardiovascular events; MI, myocardial infarction; NR, no result; TG, total triglycerides. 
flushing by preventing the production of prostaglandins. ${ }^{33-35}$ It is important to realize that the same receptor (GPR109A) is responsible for the effect on lipids and the flushing. ${ }^{17}$ Strategies addressing the flushing therefore cannot act on the niacin receptor since this would also eliminate the effect on lipids.

Another important side effect of niacin therapy is the induction of elevated glucose concentrations. This was observed in earlier studies as well as in newer trials. The underlying mechanisms are not understood, but may be related to the primary effect on free fatty acid metabolism and thus reflect insulin resistance. In most patients the effect on glucose metabolism is negligible. In patients with metabolic syndrome and borderline disturbances of glucose metabolism such as impaired fasting glucose or glucose intolerance however this may be relevant. In a study in diabetic patients 16 weeks of therapy with $1500 \mathrm{mg}$ /day niacin induced only minor changes of fasting glucose concentrations and $\mathrm{HbA}_{1 \mathrm{c}}$. However, during the course of the study oral anti-diabetic medication and insulin dose was adjusted. ${ }^{36}$ Whether the effect of niacin on glucose metabolism is clinically relevant is questionable since in the Coronary Drug Project patients benefitted from such therapy irrespective of baseline glucose level. ${ }^{37}$

\section{Laropiprant}

Since the flush induced by niacin is primarily mediated through the interaction of prostaglandin D2 with a specific receptor (prostaglandin-D2-receptor-1) a selective antagonist of this receptor was developed (MK-0524, laropiprant). ${ }^{38,39}$ Laropiprant was initially developed as a treatment for allergic rhinitis. ${ }^{39,40}$ It is eliminated primarily after glucuronidation through the liver. ${ }^{41}$ A small part of laropiprant is metabolized through cytochromP450 3A4. Laropiprant is highly selective for the prostaglandin D2-receptor-1. It can be assumed that inhibition of this receptor does not reduce the production of prostaglandins, but inhibits the vasodilatation following the formation of PGD2. Although laropiprant is a potent inhibitor of prostaglandin D2-receptor-1, it does not eliminate flushing in all patients. Higher doses of laropiprant or concomitant use of aspirin or NSAIDs cannot reduce this residual flushing. ${ }^{42,43}$ Probably other mediators such as PGE2 and serotonin, as well as their pathways, such as the beta-arrestin1/MAP kinase signaling pathway, are involved in this residual flushing. ${ }^{17,44}$

Laropiprant can also bind to the thromboxan-A2-receptor, which plays an important role thrombocyte function. ${ }^{45}$
However, in doses currently used to prevent flushing associated with niacin no clinical effects on bleeding or thrombocyte function were observed. The current, albeit short-term, studies indicate that laropiprant does not affect the lipid-modifying properties of niacin and has little sideeffects by its own. However, long-term observations are necessary to truly confirm long-term safety. It should also be noted that preliminary data indicate that other forms of flushing cannot be prevented by laropiprant.

\section{Niacin/laropiprant}

Since niacin is associated with flushing and since laropiprant can significantly reduce this flushing, it seems obvious to combine these drugs. ${ }^{46}$ Recently it was shown that the rate of moderate/severe flushing can be reduced from $50 \%$ to $24 \%$ by adding laropiprant to niacin. ${ }^{47}$ The same study showed that besides severity also frequency of flushing was reduced. Furthermore, it was recently shown in abstract form in a study involving more than 4700 patients that the addition of laropiprant to ERN reduced the rate of discontinuation due to flushing from $16.6 \%$ to $7.2 \%$ and the overall discontinuation rate from $31.5 \%$ to $25.3 \%{ }^{48}$ ERN/laropiprant patients use considerably less aspirin/ NSAID to reduce flushing compared to ERN patients (11\% vs $22 \%)^{46}$

The addition of laropiprant does not change the effect of niacin on lipids. ${ }^{49,50}$ In a study evaluating more than 1300 patients, niacin with or without laropiprant decreased LDL-cholesterol by $18.4 \%$, triglycerides by $25.8 \%$ and increased HDL-cholesterol by $20 \%{ }^{49}$ For none of the lipid parameters the effect was altered by the addition of laropiprant.

In studies evaluating the combination of niacin with laropiprant on flushing it was shown that the rate of flushing was significantly decreased compared to patients on niacin without laropiprant. ${ }^{46-49,51}$ In the group using additional laropiprant the rate of flushing was decreased to placebo level after approximately 3 months while it remained elevated in patients using niacin without laropiprant.

In a recent post hoc analysis it was also shown that niacin alone or in combination with laropiprant was associated with significant placebo-adjusted reductions from baseline in blood pressure in hypertensive or normotensive subjects with dyslipidemia. ${ }^{52}$ This may be important since it would indicate that niacin not only addresses dyslipidemia as an important cardiovascular risk factor, but has a more general beneficial effect on risk factors. Acute administration of niacin may lower blood pressure because of acute vasodilatory effects. 
From a chronic perspective, larger studies, such as the coronary drug project, suggest that niacin may lower blood pressure when administered over a longer period of time. Post hoc analyses of some of the more recent trials support a chronic, dose-dependent, blood pressure-lowering effect of niacin. Since, however, laropiprant does not attenuate niacin's blood pressure-lowering effects, it is unlikely that the chronic lowering of blood pressure is due to dilation of skin vessels through activation of the prostaglandin receptor. ${ }^{53}$

\section{Clinical use of niacin/laropiprant}

This combination may be used in patients who are considered candidates for niacin therapy. The addition of laropiprant does not alter the lipid effects but may allow using the doses necessary to achieve the full effect of niacin.

Primary candidates are patients with high risk (ie, $>20 \%$ over 10 years) who for multiple reasons do not reach lipid goals. Thus, this combination should be considered in patients who despite statin therapy have elevated LDLcholesterol in combination with elevated triglycerides and/or low HDL-cholesterol. Many of the potential candidates will have suboptimal LDL-cholesterol, triglycerides and HDL-cholesterol despite established vascular disease. Furthermore, many potential patients may be diabetic or suffer from metabolic syndrome. Niacin/laropiprant may also be a treatment option in patients who are at goal with LDL-cholesterol but have abnormal HDL-cholesterol and triglyceride concentrations (Figure 1).

The role of nicotinic acid/laropiprant is probably less clear in patients with isolated severe hypertriglyceridemia or patients with isolated LDL hypercholesterolemia. In those patients other treatment modalities are possible. Thus, in patients with isolated severe hypertriglyceridemia, lifestyle changes, which are of utmost importance, may be combined with fibrates, niacin/laropiprant, omega-3 fatty acids or rarely statins. In selected patients combinations of these drugs may be necessary. Similarly in patients with isolated LDL hypercholesterolemia despite statin therapy a number of different approaches is possible. Niacin/laropiprant, ezetimibe or a bile acid binding compound can be added, since all provide further LDL-cholesterol reduction by approximately $20 \%$ (which may vary considerably in individual patients).

Define lipid goals

Lifestyle modification

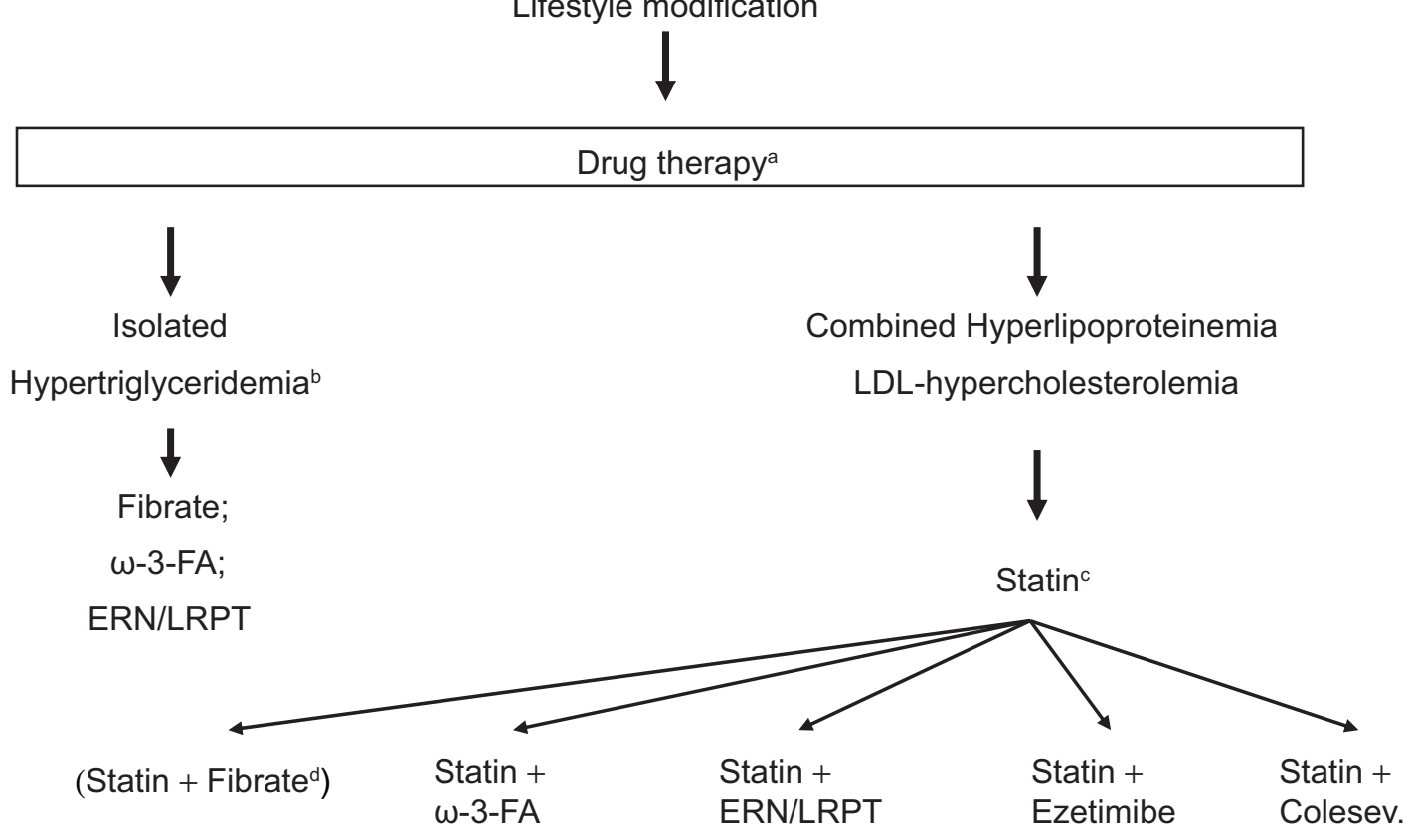

Figure I The figure describes a possible algorithm for treating patients with different forms of dyslipidemia.

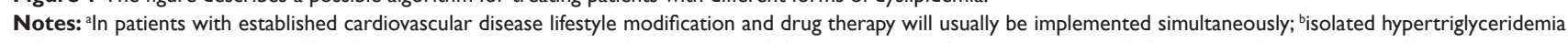
refers to a LDL-cholesterol $<100 \mathrm{mg} / \mathrm{dL}$ and elevated triglycerides; fibrates, omega- 3 fatty acids or ERN/LRPT may be used if lifestyle modification is not sufficient; in selected patients combination therapy may be necessary; ${ }^{\text {if }}$ LDL-cholesterol goal is not achieved the statin dose may be increased or switched to a more potent statin; ${ }^{d}$ statin/fibrate combination is associated with significant side effects and should therefore be only used in selected patients.

Abbreviations: $\omega$-3-FA, omega-3 fatty acids; ERN/LRPT, extended release niacin/laropiprant. 
While niacin and bile acid-binding substances have been proven to reduce $\mathrm{CHD}$ events, no such data are available for ezetimibe. On the other hand, ezetimibe is associated with fewer side effects compared to niacin and bile acid-binding substances.

Whether or not niacin/laropiprant is a treatment option for patients with elevated lipoprotein(a) remains to be determined. Although niacin may decrease lipoprotein(a) by up to $30 \%$, it is unclear whether such a modification mediates a clinical benefit. However, in patients with elevated lipoprotein(a) and recurrent cardiovascular events despite optimal treatment of all other risk factors niacin/laropiprant may be a treatment option.

Although niacin has been shown to mediate beneficial effects on cardiovascular outcome if given in monotherapy or in combination with other lipid-altering drugs, including statins, no published study has used high-dose statin monotherapy as a comparator. Thus, strictly speaking the additional benefit of niacin has not been shown in patients on statin therapy. Therefore its use should be restricted to patients at high-risk until further data are available.

Several large outcome studies will evaluate whether niacin therapy can reduce cardiovascular events. These studies will be published in 2011 or 2012. The hypothesis of AIMHIGH is that combination antidyslipidemic therapy (niacin with simvastatin) will be superior to statin monotherapy (simvastatin) when used as secondary prevention in reducing long-term clinical events in patients with documented vascular disease and atherogenic dyslipidemia. About 3300 patients will be randomized to receive simvastatin monotherapy or simvastatin with niacin.

In another study (HPS2-THRIVE) it will be evaluated whether the combination of niacin and laropiprant prevents myocardial infarctions, stroke or revascularization procedures in patients with existing vascular disease. Approximately 25,000 patients will be evaluated, including more than 7000 diabetic patients.

\section{Disclosures}

KGP has received travel rants, speaking fees or research support form AstraZeneca, Bayer, Genzyme, MSD, Novartis, Sanofi-Aventis, and Schering-Plough.

\section{References}

1. Steg PG, Bhatt DL, Wilson PW, et al. One-year cardiovascular event rates in outpatients with atherothrombosis. JAMA. 2007;297:1197-1206.

2. Hansson GK. Inflammation, atherosclerosis and coronary artery disease. N Engl J Med. 2005;352:1685-1695.

3. Baigent C, Keech A, Kearney PM, et al. Cholesterol Treatment Trialists' (CTT) Collaborators. Efficacy and safety of cholesterol-lowering treatment:prospective meta-analysis of data from 90,056 participants in 14 randomised trials of statins. Lancet. 2005;366:1267-1278.
4. Cholesterol Treatment Trialists' (CTT) Collaborators, Kearney PM, Blackwell L, Collins R, et al. Efficacy of cholesterol-lowering therapy in 18,686 people with diabetes in 14 randomised trials of statins:a meta-analysis. Lancet. 2008;371:117-125.

5. Grundy SM, Cleeman JI, Merz CN, et al. Implications of recent clinical trials for the National Cholesterol Education Program Adult Treatment Panel III guidelines. Circulation. 2004;110:227-239.

6. Graham I, Atar D, Borch-Johnsen K, et al. European guidelines on cardiovascular disease prevention in clinical practice: executive summary: Fourth Joint Task Force of the European Society of Cardiology and Other Societies on Cardiovascular Disease Prevention in Clinical Practice. Eur Heart J. 2007;28:2375-2414.

7. American Diabetes Association. Standards of Medical Care in Diabetes 2009. Diab Care. 2009;32 S1:S13-S61.

8. Altschul R, Hoffer A, Stephen JD. Influence of nicotinic acid on serum cholesterol in man. Arch Biochem. 1955;54:558-559.

9. Vogt A, Kassner U, Hostalek U, et al. Evaluations of safety and tolerability of prolonged-release nicotinic acid in a usual care setting: the NAUTILUS Study. Curr Med Res Opin. 2006;22:417-425.

10. Shepherd J, Packard DJ, Patsch JR, et al. Effects of nicotinic acid therapy on plasma high density lipoprotein subfraction distribution and composition and on apolipoptotein A metabolism. J Clin Invest. 1979;63:858-867.

11. Knopp RH. Drug treatment of lipid disorders. $N$ Engl J Med. 1999;341:498-511.

12. Coronary Drug Project Research Group. Clofibrate and niacin in coronary heart disease. JAMA. 1975;231:360.

13. Carlson LA Rosenhamer G. Reduction of mortality in the Stockholm Ischaemic Heart Disease Secondary Prevention Study by combined treatment with clofibrate and nicotinic acid. Acta Med Scand. 1988;223:405.

14. McKenney JM, Jones PH, Bays HE, et al. Comparative effects on lipid levels of combination therapy with a statin and extended-release niacin or ezetimibe versus a statin alone (the COMPELL study). Atherosclerosis. 2007;192:432-437.

15. Capuzzi DM, Guyton JR, Morgan JM, et al. Efficacy and safety of an extended-release niacin (Niaspan):a long-term study. Am J Cardiol. 1998;82:74U-81U.

16. Kamanna VS, Ganji SH, Kashyap ML. Niacin:an old drug rejuvenated. Curr Atheroscler Rep. 2009;11:45-51.

17. Benyo Z, Gille A, Kero J. GPR109A (PUMA-G/HM74A) mediates nicotinic acid-induced flushing. J Clin Invest. 2005;115:3634-2640.

18. Carlson LA, Orö L. The effect of nicotinic acid on the plasma free fatty acids. Acta Med Scand. 1962;172:641-645.

19. Carlson LA. Nicotinic acid: the broad spectrum lipid drug. A 50th anniversary review. J Intern Med. 2005;258:94-114.

20. Van JT, Pan J, Wasty T, et al. Comparison of extended-release niacin and atorvastatin monotherapies and combination treatment of the atherogenic lipid profile in diabetes mellitus. Am J Cardiol. 2002;89:1306.

21. Davidson MH. Novel nonstatin strategies to lower low-density lipoprotein cholesterol. Curr Atheroscler Rep. 2009;11:67-70.

22. Brown BG, Zhao XQ Chait A, et al. Simvastatin and niacin, antioxidant vitamins, or the combination for the prevention of coronary disease. N Engl J Med. 2001;345:1583-1592.

23. Canner PL, Berge KH, Wenger NK, et al. Fifteen year mortality in coronary drug project patients: long-term benefit with niacin. $J \mathrm{Am}$ Coll Cardiol. 1986;8:1245.

24. Blankenhorn DH, Nessim SA, Johnson RL, et al. Beneficial effects of combined colestipol-niacin therapy on coronary atherosclerosis and coronary venous bypass grafts. JAMA. 1987;257:3233-3240.

25. Taylor AJ, Sullenberger LE, Lee HJ, et al. Arterial Biology for the Investigation of the Treatment Effects of Reducing Cholesterol (ARBITER) 2: a double-blind, placebo-controlled study of extendedrelease niacin on atherosclerosis progression in secondary prevention patients treated with statins. Circulation. 2004;110:3512-3517.

26. Taylor AJ, Lee HJ, Sullenberger LE. The effect of 24 months of combination statin and extended-release niacin on carotid intima-media thickness: ARBITER 3. Curr Med Res Opin. 2006;11:2243-2250. 
27. Singh IM, Shishehbor MH, Ansell BJ. High-density lipoprotein as a therapeutic target:a systematic review. JAMA. 2007;298:786-798.

28. Zhao XQ, Morse JS, Dowdy AA, et al. Safety and tolerability of simvastatin plus niacin in patients with coronary artery disease and low high-density lipoprotein cholesterol (The HDL Atherosclerosis Treatment Study). Am J Cardiol. 2004;93:307-312.

29. Rubenfire M. Safety and compliance with once-daily niacin extended-release/lovastatin as initial therapy in the Impact of Medical Subspeciality on Patient Compliance to Treatment (IMPACT) Study. Am J Cardiol. 2004;94:306-311.

30. Morrow JD, Awad JA, Oates JA, et al. Identification of skin as a major site of prostaglandin D2 release following oral administration of niacin in humans. J Invest Dermatol. 1992;98:812-815.

31. Ishida H, Masuhio Y, Fukushima A, et al. Identification and characterization of novel isoforms of human DP-1:DP-1 (alpha) regulates the transcriptional activity of E2F1 as well as cell cycle progression in a dominant-negative manner. J Biol Chem. 2005;280:24642-24648.

32. Cheng K, Wu TJ, Wu KK, et al. Antagonism of the prostaglandin $\mathrm{D}_{2}$ receptor 1 suppresses nicotinic acid-induced vasodilation in mice and humans. Proc Natl Acad Sci U S A. 2006;103:6682-6687.

33. Jungnickel PW, Maloley PA, Vander Tuin EL, Peddicord TE, Campbell JR. Effect of two aspirin pretreatment regimens on niacininduced cutaneous reactions. J Gen Intern Med. 1997;12:591-596.

34. Wilkin JK, Wilkin O, Kapp R, Donachie R, Chernosky ME, Buckner J, et al. Aspirin blocks nicotinic acid-induced flushing. Clin Pharmacol Ther. 1982;31:478-482.

35. Dunn RT, For MA, Rindone JP, Kwiecinski FA. Low-dose aspirin and ibuprofen reduce the cutaneous reactions following niacin administration. Am J Ther. 1995;2:478-480.

36. Grundy SM, Vega GL, McGovern ME, et al. Efficacy, safety, and tolerability of once-daily niacin for the treatment of dyslipidemia associated with type 2 diabetes: results of the assessment of diabetes control and evaluation of the efficacy of niaspan trial. Arch Intern Med. 2002; $162: 1568$.

37. Canner PL, Furberg CD, Terrin ML, McGovern ME. Benefits of niacin by glycemic status in patients with healed myocardial infarction (from the Coronary Drug Project). Am J Cardiol. 2005;95:254-257.

38. Dean BJ, Chang S, Silva Elipe MV, et al. Metabolism of MK-0524, a prostaglandin $\mathrm{D}_{2}$ receptor 1 antagonist, in microsomes and hepatocytes from preclinical species and humans. Drug Metab Dispos. 2007;35:283-292.

39. Sturino CF, O'Neill G, Lachance N, et al. Discovery of a potent and selective $\mathrm{PGD}_{2}$ receptor antagonist [(3R)-4-(4-chlorobenzyl)-7-fluoro5-(methylsulfonyl)-1,2,3,4-tetrahydrocyclopentaindol-3-yl]-acetic acid (MK-0524). J Med Chem. 2007;50:794-806.

40. Van Hecken A, Depré M, De Lepeleire I, et al. The effect of MK-0524, a prostaglandin $\mathrm{D}(2)$ receptor antagonist, on prostaglandin $\mathrm{D}(2)$-induced nasal airway obstruction in healthy volunteers. Eur J Clin Pharmacol. 2007;63:135-141.
41. Bindhu K, Maria M, Scott B, et al. Absorption, metabolism, and excretion of [14C]MK-0524, a prostaglandin D2 receptor antagonist, in humans. Drug Metab Dispos. 2007:35:1196.

42. Lai E, Wenning LA, Crumley TM, et al. Pharmacokinetics, pharmacodynamics, and safety of a prostaglandin D2 receptor antagonist. Clin Pharmacol Ther. 2008;83:840-847.

43. Dishy V, Liu F, Ebel DL, Atiee GJ, et al. Effects of aspirin when added to the prostaglandin D2 receptor antagonist laropiprant on niacin-induced flushing symptoms. J Clin Pharmacol. 2009;49:416-422.

44. Papaliodis D, Boucher W, Kempuraj D, et al. Niacin-induced "flush" involves release of prostaglandin D2 from mast cells and serotonin from platelets: evidence from human cells in vitro and an animal model. J Pharm Exp Ther. 2008:327:665-672.

45. Felts AS. Molecule of the month. TREDAPTIVE (nicotinic acid/ laropiprant): a new lipid-modifying therapy for the treatment of LDL-C, HDL-C and triglycerides. Curr Top Med Chem. 2008;14:1310.

46. Maccubbin D, Koren MJ, Davidson M, et al. Flushing profile of extended-release niacin/laropiprant versus gradually titrated niacin extended-release in patients with dyslipidemia with and without ischemic cardiovascular disease. Am J Cardiol. 2009;104:74-81.

47. Kush D, Hu DY, Ye P, et al. Flushing profile of extended-release niacin/laropiprant at initiation of therapy in Asian lipid clinic patients. Cardiology. 2009;114:192-198.

48. McKenney J, Bays H, Koren M, et al. Safety profile of extendedrelease niacin/laropiprant in patients with dyslipidemia. Abstracts 77th Congress of the European Atherosclerosis Society. Atherosclerosis Suppl. 2008;9(1):194-195.

49. Maccubbin D, Bays HE, Olsson Ag, et al. Lipid-modifying efficacy and tolerability of extended-release niacin/laropiprant in patients with primary hypercholesterolaemia or mixed dyslipidaemia. Int J Clin Pract. 2008;62:1959-1970.

50. Gleim G, Ballantyne CM, Liu N, et al. Efficacy and safety profile of co-administered ER niacin/laropiprant and simvastatin in dyslipidaemia. Br J Cardiol. 2009;16:90-97.

51. Paolini JF, Mitchel YB, Reyes R, Effects of laropiprant on nicotinic acid-induced flushing in patients with dyslipidemia. Am J Cardiol. 2008;101:625-630.

52. Bays HE, Maccubbin D, Meehan AG, et al. Blood pressure-lowering effects of extended-release niacin alone and extended-release niacin/ laropiprant combination: a post hoc analysis of a 24-week, placebocontrolled trial in dyslipidemic patients. Clin Ther. 2009;31:115-122.

53. Bays HE, Rader DJ. Does nicotinic acid (niacin) lower blood pressure? Int J Clin Pract. 2009;63:151-159.
Vascular Health and Risk Management

\section{Publish your work in this journal}

Vascular Health and Risk Management is an international, peerreviewed journal of therapeutics and risk management, focusing on concise rapid reporting of clinical studies on the processes involved in the maintenance of vascular health; the monitoring, prevention and treatment of vascular disease and its sequelae; and the involvement of

\section{Dovepress}

metabolic disorders, particularly diabetes. This journal is indexed on PubMed Central and MedLine. The manuscript management system is completely online and includes a very quick and fair peer-review system, which is all easy to use. Visit http://www.dovepress.com/ testimonials.php to read real quotes from published authors. 